\title{
Study of Nanocomposites of Silicon Structures for use in Mechatronics
}

\author{
Stefan Kartunov* \\ Department of Mechanical and Precision Engineering, Technical University of Gabrovo, Bulgaria
}

*Corresponding author: Stefan Kartunov, Department of Mechanical and Precision

Engineering, Technical University of Gabrovo, Bulgaria.

\begin{abstract}
This article analyzes the developments on the subject and draws conclusions for the study 1722/M - 2017 at the UZNIT of TU - Gabrovo BG. Most metals are highly chemically reactive, especially at nanoscale, without having properties that can be easily used with TiO2 composites. As such, most of the metals below will be considered metal oxides of precious metals. In addition, the most common oxide TiO2 will be discussed, as other oxides are probably unstable and thus do not form stable composites.
\end{abstract}

Keywords: Nanocomposites; Silicon structures; Titanium dioxide

\section{Introduction}

A detailed consideration of all precious metals is given in study $1722 / \mathrm{M}-2017$ at the UZNIT of Technical University-Gabrovo and [1]. Only palladium, platinum, silver and gold are considered here.

\section{Technical Requirements}

The development of $\mathrm{Pd} / \mathrm{TiO}_{2}$-based palladium composites on visible light radiation was studied by Mohapatra. $\mathrm{TiO}_{2}$ nanoparticles were synthesized by Ti foil anodization followed by $\mathrm{PdCl}_{2}$ functionalization and subsequent $\mathrm{H}_{2} / \mathrm{Ar}$ calcining to crystallize $\mathrm{TiO}_{2}$ and converting the Pd salt to pure Pd. The synthesized composite with optimized $1.25 \mathrm{wt} \% \mathrm{Pd}$ showed significant photocatalytic improvement compared to naked $\mathrm{TiO}_{2}$ nanotubes. A nitrogen-dosed $\mathrm{Pd} / \mathrm{TiO}_{2}$-active to the visible light composite is also prepared. Prepared $\mathrm{TiO}_{2}$ nanotube matrices through a three-stage anodization of Ti foil, followed by calcination and hydrothermal reduction of Pd-nanoparticles on the crystal $\mathrm{TiO}_{2}$ nanotubes in the presence of polyvinylpyrrolidone (PVP) and Na I allow for controlling the PVP-concentration and the hydrothermal reaction time. Figures 1a and $1 \mathrm{~b}$ show a Scanning electron microscope (SEM)-image of a preconditioned nanotube matrix, and Figures $1 \mathrm{c}$ and $1 \mathrm{~d}$ show the mass after hydrothermal deposition of Pd. Figure 1 shows a Tunnel elec tron microscope (TEM)-image of the nanotube with clearly placed Pd-nanoparticles. No such silicon matrix composites are known.

Photocatalytic production of $\mathrm{Pt} / \mathrm{TiO}_{2}$ composites consistently shows increasing growth with the advancement of nanoscale synthesis and controllable/tunable properties of nanomaterials. These composites allow optimization of parameters such as morphology, crystalline phase, crystallinity, porosity and surface area, each of which can alter the photoactivity of the composition. Improving photocatalytic activity with the introduction of $\mathrm{Pt}$ is typically attributed to the formation of a Schottky barrier at the metal- $\mathrm{TiO}_{2}$ interface. This happens because the work function of Pt $(\sim 5,36-5,63$ $\mathrm{eV})$ is greater than that of $\mathrm{TiO}_{2}(\sim 4,6-4,7 \mathrm{eV})$, so that electrons are transferred at $\mathrm{Pt}$ and holes Localized in $\mathrm{TiO}_{2}$ media to improve photocatalytic efficiency. In order to improve the $\mathrm{Pt} / \mathrm{TiO}_{2}$ composites, steps have been taken to optimize the interaction between Pt and $\mathrm{TiO}_{2}$ from Kandiel, effectively effecting the surface area and crystal structure of $\mathrm{TiO}_{2}$ in the resulting $\mathrm{Pt} / \mathrm{TiO}_{2}$ composite and demonstrating that although the large Area is useful, increasing crystallinity is preferential. Increasing photocatalytic activity is due to the reduction of site defects that act as charge recombination centers when crystallinity increases. 


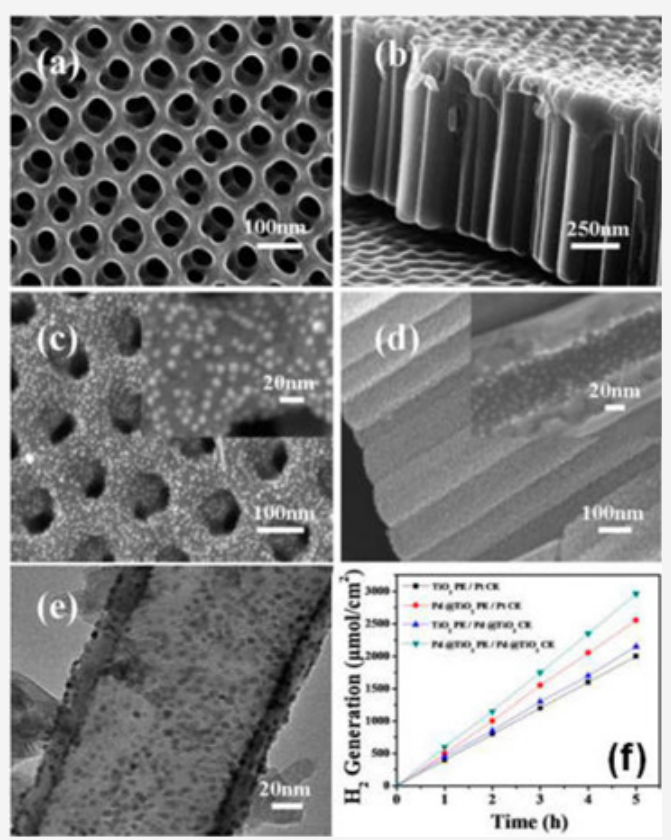

Figure 1: (a) and (b) Scanning electron microscope (SEM)-images in cross-section of nanotubes TiO2 (TNTAs) obtained from electrochemical anodization. SEM-images of Pd composites deposited on TNTAs: (c) a top view of small and large magnifications; (d) a cross-sectional view (a large magnification of a broken tube is shown in the insert). (d) Tunnel electron microscope (TEM)-image of TiO2 nanotubes with deposited Pd composites showing that they are uniformly dispersed on nanotubes. f) A graph of the amount of hydrogen generated by TiO2 nanotubes and $\mathrm{Pd} / \mathrm{TNTA}$ nanocomposites such as photon and Pt foil and $\mathrm{Pd} / \mathrm{TNTA}$ nanocomposites as cathodes. $\mathrm{Pd} \%=2.15 \%$ wt. PE and CE respectively indicate photo anode and cathode electrodes.

Due to their low price compared to other precious metals, intensive localized surface plasma resonance (LSPR) and easy shape control, silver nanomaterials are used in $\mathrm{TiO}_{2}$ composites to a considerable extent. Silver is widely used with $\mathrm{TiO}_{2}$ to produce composites to decompose photocatalytic organic molecules, DSS-composites, photoactive bactericides, photochromic materials and other applications. Although silver cannot recombine $\mathrm{H}+$ atoms for hydrogen production, based on its slightly larger function, $\sim 4.7$ and $4.6 \mathrm{eV}$ for $\mathrm{Ag}$ and $\mathrm{TiO}_{2}$, respectively still can attract photogenerated electrons of $\mathrm{TiO}_{2}$ and thus improve the separation of the charge.
Many reports show improved UV-photocatalytic degradation of organic pollutants from $\mathrm{Ag} / \mathrm{TiO}_{2}$ composites compared to pure $\mathrm{TiO}_{2}$. Although the precise nature of LSPR-resonance on improved photocatalytic activity has not been fully investigated, it improves the photocatalytic activity of $\mathrm{TiO}_{2}$ and the generation of photoelectrochemical currents. In the Awazu study, direct contact between Ag and $\mathrm{TiO}_{2}$ is not necessary for photocatalytic amplification, which suggests that the reason is the increase of the Ag LSPR-resonance electromagnetic field.

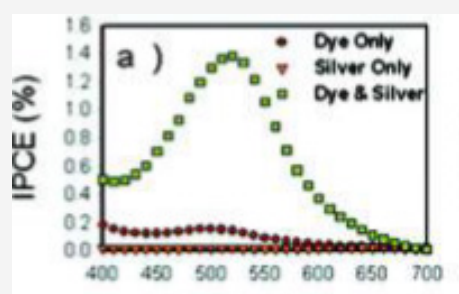

Wavelength $(\mathrm{nm})$

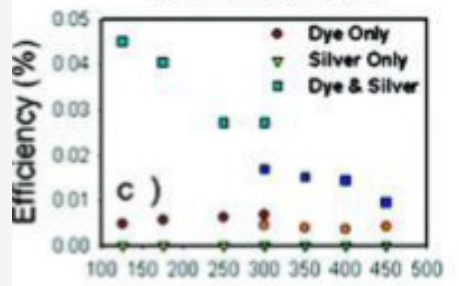

$\mathrm{TiO}_{2}$ Cycles

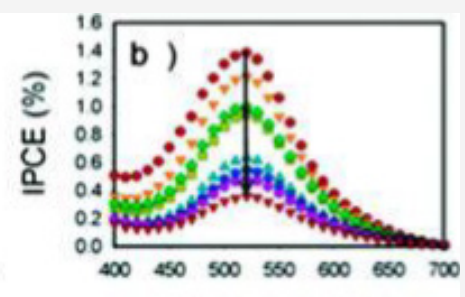

Wavelength $(\mathrm{nm})$

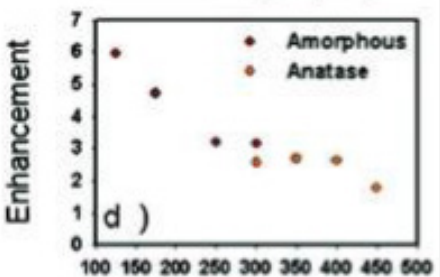

$\mathrm{TiO}_{2}$ Cycles

Figure 2: IPCE and general trends in cells. (a) IPCE for cells with 125 cycles of amorphous $\mathrm{TiO}_{2}$. (b) IPCE for silver-plated cells. The indicator shows an increase in $\mathrm{TiO}_{2}$ thickness. The first four spectra and the two spectra correspond to amorphous and anode $\mathrm{TiO}_{2}$. (c) Cell efficiency. Dark blue, orange and green symbols match the anatomy samples. Light blue, red, and yellow symbols correspond to amorphous samples. (d) Calculated plasma increase factor as a function of $\mathrm{TiO}_{2}$ thickness. 
In this study, silver nanoparticles are embedded in $\mathrm{SiO}_{2}$ layers of varying thickness, followed by a $\mathrm{TiO}_{2}$ layer, which is of interest to the topic. It is shown that when the $\mathrm{SiO}_{2}$ layer is thinner, photocatalytic degradation increases even without contact with $\mathrm{TiO}_{2}$. The system consists of $\mathrm{Ag}$ nanoparticles, coated with different $\mathrm{TiO}_{2}$ thickening particles. As shown in Figure $2 \mathrm{~b}, \mathrm{TiO}_{2}$ 's finest coatings give the greatest improvement in IPCEs, due to the larger electromagnetic field attributed to silver nanoparticles. This in turn leads to greater cellular efficacy as shown in Figure 2c.

In order to better investigate the effects of the metal- $\mathrm{TiO}_{2}$ interaction in the $\mathrm{Ag} / \mathrm{TiO}_{2}$ composite, core $\mathrm{Ag} / \mathrm{TiO}_{2}$ structures were synthesized. The original core composites were manufactured by Liz-Marzan and others, but the $\mathrm{Ag} / \mathrm{TiO}_{2}$ composite nuclear coatings specifically made for interaction studies were first synthesized and tested by Hirakawa and Kamat. Reversible charge and dilution of the Ag core of photocurrent electrons from the $\mathrm{TiO}_{2}$ shell is observed, and when the composite is irradiated, the electrons are moved to the $\mathrm{Ag}$ core because the holes generated in $\mathrm{TiO}_{2}$ are extracted from ethanol. Details can be seen in study 1722/M-2017.

Compared to platinum and silver, gold has advantages over each of them. Like silver, gold has an adjustable LSPR-resonance, that can be used to improve photocatalytic activity, but also has a stronger chemical stability similar to platinum. In addition, gold has a high duty function $(\sim 5.1-5.3 \mathrm{eV})$. Based on this, the $\mathrm{Au} / \mathrm{TiO}_{2}$ composites are used for many of the same applications as Pt and $\mathrm{Ag}$, with some improvements depending on the case. Typically, $\mathrm{Au} /$ $\mathrm{TiO}_{2}$ composites have a better $\mathrm{Ag} / \mathrm{TiO}_{2}$ photoactivity because the higher gold function compared to silver allows better separation of the $\mathrm{TiO}_{2}$ charge. In addition to applications for degradation of organic molecules and hydrogen production, the $\mathrm{Au} / \mathrm{TiO}_{2}$ composites are heavily used for $\mathrm{CO}$ oxidation, which is of importance to the environment due to its release from combustion of fuels in internal combustion engines. It is known that $\mathrm{Au} / \mathrm{TiO}_{2}$ composites effectively convert $\mathrm{CO}$ to $\mathrm{CO}_{2}$, even at temperatures below $0{ }^{\circ} \mathrm{C}$. Various factors may influence the activity of $\mathrm{CO} / \mathrm{CO}_{2}$ oxidants, the particle size of $\mathrm{Ag}$, but also the $\mathrm{TiO}_{2}$ crystallinity and the method of composing the composite. The deactivation of the composite, due to Au particle sintering, is particularly important because in practical applications such as catalytic converters the composite would be subjected to high temperatures $\left(>750{ }^{\circ} \mathrm{C}\right)$. In order to prevent this deactivation, Lee's study uses an $\mathrm{Au} / \mathrm{TiO}_{2}$ catalyst of methyl-orange that can effectively prevent the sintering of Au nanoparticles by placing a physical $\mathrm{TiO}_{2}$ barrier.

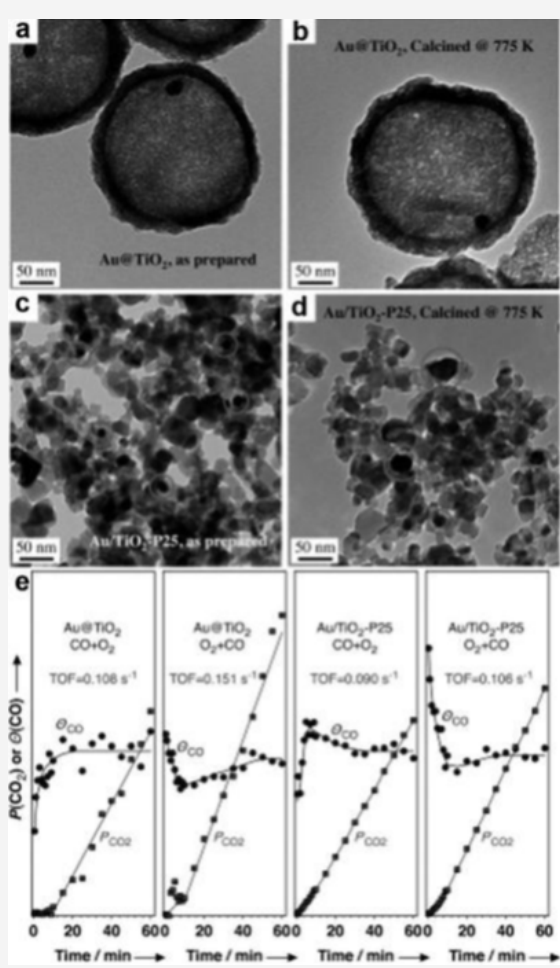

Figure 3: (a) TEM-image of the prepared Au/TiO2 structure. (b) TEM-image of the Au/TiO ${ }_{2}$ calcite structure. c) TEM-image of the prepared Au/ P25 sample. d) TEM-image of the Au /P25 sample after calcification. e) Time dependence of carbon oxide coating on gold and partial pressure of carbon dioxide during oxidation of $\mathrm{CO}$ at room temperature of $\mathrm{CO}$ with gold/titanium base catalysts. The two left panels correspond to the Au/ $\mathrm{TiO}_{2}$ catalyst and the right panel to the reference $\mathrm{Au} / \mathrm{TiO}_{2}-\mathrm{P} 25$ sample. First and third panels are obtained by first introducing $\mathrm{CO}$ at a pressure of 200 Torr into the cell; In the second and fourth panel the sequence is reversible. CO coating of Au in gas phase $\mathrm{CO}_{2}$ is calculated from the integrated intensities of DRIFT signals in the regions $2090-2145$ and $2300-2400 \mathrm{~cm}^{-1}$ respectively.

In this study is suggested an $\mathrm{Au} / \mathrm{TiO}_{2}$ composite consisting of a nanoparticle of gold $(\sim 15 \mathrm{~nm})$ in porous $\mathrm{TiO}_{2}$ and is also available. The composite is made by applying the nanoparticles Au first with a $\mathrm{SiO}_{2}$ layer and then coating the $\mathrm{TiO}_{2}$ layer composite. The $\mathrm{SiO}_{2}$ can then be removed from the composite by dissolution with $\mathrm{NaOH}$ as shown in Figure 3a. The composite can then be calcined and crys- 
tallized $\mathrm{TiO}_{2}$ without alteration of the Au nanoparticles, as shown in Figure $3 \mathrm{~b}$. This result is compared with the $\mathrm{Au} / \mathrm{TiO}_{2}-\mathrm{P} 25$ composite calcification, where Au nanoparticles are synthesized significantly (Figure 3d). All this and the application is the subject of further research.

\section{Conclusion}

- $\quad$ No precious metal (Pd) composites of silicon matrix and metal oxides- $\mathrm{TiO}_{2}$ are known.

- In this study, silver nanoparticles are proposed to be embedded in $\mathrm{SiO}_{2}$-layers of varying thickness, followed by a $\mathrm{TiO}_{2}$ layer. It is shown that when the $\mathrm{SiO}_{2}$ layer is thinner, photocatalytic degradation increases even without contact with $\mathrm{TiO}_{2}$.

- $\mathrm{An} \mathrm{Au} / \mathrm{TiO}_{2}$ composite, consisting of a nanoparticle of gold $(\sim 15 \mathrm{~nm})$ in porous $\mathrm{TiO}_{2}$ is synthesized. The composite is made by applying the nanoparticles $\mathrm{Au}$ first with a $\mathrm{SiO}_{2}$ layer and then coating the $\mathrm{TiO}_{2}$ layer composite. The $\mathrm{SiO}_{2}$ can then be removed from the composite by dissolution with $\mathrm{NaOH}$. The composite can then be calcined and crystallized $\mathrm{TiO}_{2}$ without alteration in the $\mathrm{Au}$ nanoparticles. All this is the subject of further research on solar collectors.

\section{Acknowledgement}

None.

\section{Conflict of Interest}

No conflict of interest.

\section{References}

1. Kurtunov S (2012) Technological bases in mechatronics, micro-and Nanosystem Technics. Textbook-monograph, Gabrovo, and C Aprilov, Bulgaria. 